\title{
Effect of vildagliptin add-on treatment to metformin on plasma asymmetric dimethylarginine in type 2 diabetes mellitus patients
}

\author{
This article was published in the following Dove Press journal: \\ Drug Design, Development and Therapy \\ 14 February 2014 \\ Number of times this article has been viewed
}

\author{
Mustafa Cakirca' \\ Cumali Karatoprak' \\ Mehmet Zorlu' \\ Muharrem Kiskac' \\ Mustafa Kanat ${ }^{2}$ \\ Mehmet Ali Cikrikcioglu' \\ Pinar Soysal ${ }^{3}$ \\ Mehmet Hursitoglu ${ }^{4}$ \\ Ahmet Adil Camli' \\ Reha Erkoc' \\ Muhammad Abdul-Ghani ${ }^{5}$ \\ 'Internal Medicine Clinic, Faculty of \\ Medicine, Bezmialem Vakif University, \\ ${ }^{2}$ Department of Internal Medicine, \\ Medical Faculty, Istanbul Medipol \\ University, ${ }^{3}$ Department of Geriatric \\ Medicine, Medical Faculty, Dokuz \\ Eylül University, ${ }^{4}$ Department of \\ Internal Medicine, Kanuni Sultan \\ Suleyman Training and Research \\ Hospital, Istanbul, Turkey; ${ }^{5}$ Division \\ of Medicine - Diabetes, University of \\ Texas Health Science Center at San \\ Antonio, San Antonio, TX, USA
}

Correspondence: Cumali Karatoprak Internal Medicine Clinic, Faculty of Medicine, Bezmialem Vakif University, Adnan Menderes Bulvarı Vatan Caddesi, Fatih, Istanbul 34093, Turkey

Tel +90 2I $2453 \quad$ I700 ext 1074

Fax +902125332326

Email ckaratoprak@hotmail.com

\begin{abstract}
Aims: A close association has been demonstrated between increased cardiovascular risk and high asymmetric dimethylarginine (ADMA) levels in type 2 diabetes mellitus (DM) patients. We planned to measure serum ADMA levels in type 2 DM patients using vildagliptin, a dipeptidyl peptidase-4 (DPP-4) inhibitor.
\end{abstract}

Materials and methods: A total of 68 type 2 DM patients who were on metformin were enrolled in the study. Based on the glycemic levels of patients, vildagliptin was added on to treatment in 33 patients. Patients were followed for 6 months. Serum ADMA, C-reactive protein, and fibrinogen levels were compared in groups of patients using metformin or metformin + vildagliptin, after 6 months.

Results: Serum ADMA levels were found to be significantly lower in the group using vildagliptin compared to the group using metformin + vildagliptin $(P<0.001)$. However, serum $\mathrm{C}$-reactive protein and fibrinogen levels were statistically similar in the two study groups $(P=0.34$ and $P=0.23$, respectively).

Conclusion: Metformin + vildagliptin treatment was observed to lower serum ADMA levels in type 2 DM patients. Our findings notwithstanding, large-scale prospective randomized controlled studies are warranted to conclude that vildagliptin provides cardiovascular protection along with diabetes regulation.

Keywords: asymmetric dimethylarginine (ADMA), dipeptidyl peptidase-4 (DPP-4) inhibitor, vildagliptin, type 2 diabetes mellitus

\section{Introduction}

Cardiovascular events are known to be increased by two- to fourfold in patients with type 2 diabetes mellitus (DM). Cardiovascular events rank first among the reasons for death in type 2 DM patients. ${ }^{1}$ Therefore, it is important that drugs employed in the treatment of type 2 DM have beneficial effects on cardiovascular protection.

One of the drug classes used in the treatment of type $2 \mathrm{DM}$ are endogenous dipeptidyl peptidase-4 (DPP-4) inhibitors. Owing to the development of DPP-4 inhibitors, the half-life of endogenous glucagon-like peptide-1 (GLP-1) is prolonged through the inhibition of GLP-1 degradation. ${ }^{2,3}$ The increased endogenous plasma GLP-1 concentration is thought to exhibit protective effects on the cardiovascular system. ${ }^{4,5}$

Increased basal plasma levels of asymmetric dimethylarginine (ADMA), the endogenous nitric oxide synthase inhibitor, is known to cause endothelial dysfunction and atherosclerosis. ${ }^{6}$ A close association has been demonstrated between increased 
cardiovascular risk and increased serum ADMA levels in studies conducted on diabetic patients. ${ }^{4}$ Serum ADMA level was also sought with the DPP-4 inhibitor saxagliptin in an animal study. ${ }^{7}$ The findings of that study suggest that the DPP-4 inhibitors could affect serum ADMA levels.

In our study, we planned to measure serum levels of ADMA, which is thought to be closely associated with increased cardiac risk, in type $2 \mathrm{DM}$ patients using vildagliptin.

\section{Materials and methods}

In our study, 68 patients over 18 years old with type 2 DM and who were on metformin only (1,000 mg twice daily) were enrolled. Based on the glycemic levels of patients, vildagliptin (50 mg twice daily) was added on in 33 patients. Patients were followed for a duration of 6 months. A group of type 2 DM patients who were treated with metformin and had good glycemic control (glycated hemoglobin $\left[\mathrm{HbA}_{1 \mathrm{c}}\right]<7.0 \%$ ) comprised group 1. Metformin-treated type $2 \mathrm{DM}$ patients with poor glycemic control $\left(\mathrm{HbA}_{1 \mathrm{c}}>6.5 \%\right)$ were identified, vildagliptin was added as a second-line therapy, and they comprised group 2. This group was matched to subjects in the first group. Serum ADMA level is known to be affected by such disorders as hypercholesterolemia, atherosclerosis, hypertension, chronic heart failure, DM, and chronic renal insufficiency. It is also known that certain medications, such as calcium-channel blockers, beta-blockers, angiotensinconverting enzyme inhibitors, and angiotensin-receptor blockers affect serum ADMA levels. Therefore, patients using diabetic medicines other than metformin, those who had any other additional disorders, and/or were using additional drugs were excluded from the study. Also, patients that were currently on DPP-4 inhibitor treatment or GLP-1 receptor-agonist treatment, had acute coronary syndrome within the last 6 months or liver disease or overt nephropathy (albuminuria $>300 \mathrm{mg} /$ day), or pregnant patients were excluded from the study. The study was initiated after ethical committee approvals of both the Ministry of Health and Bezmialem Vakif University.

Venous blood samples were obtained from the patients enrolled in the study at between 8 and 9 am following at least 10-12 hours of fasting. Patients' blood samples were used to measure the following laboratory values: ADMA (BioTek ${ }^{\mathrm{TM}}$ ELx 50 washer and ELx 800 reader using ADMA Xpress human commercial kit; Thermo Fisher Scientific, Waltham, MA, USA), C-reactive protein (CRP) (Cobas ${ }^{\circledR} 501$ system, using immunoturbidimetric method; Roche, Basel, Switzerland), fibrinogen (optical measurement method on an AMAX-200 full automatic coagulation apparatus, using a TriniCLOT fibrinogen kit; Tcoag, Wicklow, Ireland), $\mathrm{HbA}_{1 \mathrm{c}}$ (turbidimetric inhibition immunoassay; Roche), low-density lipoprotein cholesterol (LDL-C), high-density lipoprotein cholesterol (HDL-C), triglyceride, hemogram, and alanine aminotransferase (ALT) and creatinine values (immunoassay chemiluminescent method; Beckman Coulter, Pasadena, CA, USA).

\section{Statistical analysis}

For the assessment of study findings, SPSS for Windows 13.0 (IBM, Armonk, NY, USA) was used in statistical analyses. We computed that 30 subjects in each group provided $95 \%$ power to detect $20 \%$ difference between the two groups, with an alpha of 0.05 . To ensure 30 completers in each group, we set the sample size at 35 in each group.

During the assessment of study findings, along with definitive statistical methods (mean, median, standard deviation), Student's $t$-test was used to compare normally distributed parameters, and the Mann-Whitney $U$ test was used to compare abnormally distributed parameters. The $\chi^{2}$ test was employed to compare the proportional data. A twosided $P$-value of $<0.05$ was considered significant.

\section{Results}

There were 16 women (M:F =19:16) in the type 2 DM group using metformin $(n=35)$, and eleven women $(M: F=22: 11)$ in the metformin + vildagliptin group $(n=33)$, with no statistically significant difference between the groups $(P=0.09)$. No significant differences were found upon the comparison of age, body mass index (BMI), waist circumference, diabetes duration, or the last of $\mathrm{HbA}_{1 \mathrm{c}}$, LDL-C, HDL-C, triglyceride, ALT, and creatinine values of patients (Table 1).

Table I Demographic and laboratory characteristics of patients by group

\begin{tabular}{|c|c|c|c|}
\hline & $\begin{array}{l}\text { Metformin } \\
(n=35)\end{array}$ & $\begin{array}{l}\text { Met-vildagliptin } \\
(n=33)\end{array}$ & $P$-value \\
\hline & Mean \pm SD & Mean \pm SD & \\
\hline Age (years) & $52.1 \pm 6.5$ & $49.8 \pm 8.7$ & 0.21 \\
\hline BMI $\left(\mathrm{kg} / \mathrm{m}^{2}\right)$ & $30.5 \pm 4.5$ & $29.4 \pm 4.9$ & 0.34 \\
\hline Waist circumference $(\mathrm{cm})$ & $106 \pm 10.6$ & $103 \pm 9.6$ & 0.27 \\
\hline Diabetes duration (years) & $3.1 \pm 3$ & $4.6 \pm 3.8$ & 0.11 \\
\hline Baseline $\mathrm{HbA}_{1 \mathrm{c}}(\%)$ & $6.5 \pm 1.3$ & $7.3 \pm 1.5$ & 0.02 \\
\hline After treatment $\mathrm{HbA}_{\mathrm{Ic}}(\%)$ & $6.5 \pm 1.4$ & $7.0 \pm 1.5$ & 0.15 \\
\hline LDL-C (mg/dL) & $|33 \pm 3|$ & $132 \pm 24$ & 0.94 \\
\hline HDL-C (mg/dL) & $49 \pm 13$ & $47 \pm 11$ & 0.46 \\
\hline Triglyceride (mg/dL) & $156 \pm 93$ & $146 \pm 80$ & 0.66 \\
\hline $\operatorname{ALT}(\mathrm{U} / \mathrm{L})(10-40)$ & $28.5 \pm 22.7$ & $32.7 \pm 28.4$ & 0.45 \\
\hline Creatinine (mg/dL) & $0.74 \pm 0.14$ & $0.78 \pm 0.19$ & 0.38 \\
\hline
\end{tabular}

Abbreviations: SD, standard deviation; $\mathrm{BMI}$, body mass index; $\mathrm{HbA}_{1 \mathrm{l}}$, glycated hemoglobin; LDL-C, low-density lipoprotein cholesterol; HDL-C, high-density lipoprotein cholesterol; ALT, alanine aminotransferase; Met-vildagliptin, metformin + vildagliptin. 
Serum ADMA, CRP, and fibrinogen levels were measured concurrently in the groups of type $2 \mathrm{DM}$ patients using metformin or metformin + vildagliptin. Upon comparison of these values, serum ADMA levels were detected to be significantly lower in patients with vildagliptin added on to metformin $(P<0.001)$. However, CRP and fibrinogen levels were found to be similar in the two groups of patients (Table 2).

Upon assessment of patients whose ADMA levels were in the normal range versus those with high ADMA levels, only four (11.4\%) patients in the metformin-using group had ADMA levels within the normal range, whereas $31(88.6 \%)$ patients had increased ADMA levels. As for the group of patients with vildagliptin added on to metformin, 17 (51.5\%) patients had ADMA levels within the normal range, and $16(48.5 \%)$ patients had increased levels of ADMA (Figure 1).

\section{Discussion}

In our study, we observed that add-on treatment with vildagliptin decreased serum ADMA levels with statistical significance in type $2 \mathrm{DM}$ patients using metformin. This might be of importance in providing cardiovascular protection in patients with type $2 \mathrm{DM}$, because diabetes has long been known to be a major cardiovascular risk factor. Numerous studies have been conducted to demonstrate that diabetes in patients causes an increase in cardiovascular risk. The EUROASPIRE (European Action on Secondary Prevention through Intervention to Reduce Events) III trial covering the European population found that $25 \%$ of patients with cardiovascular disorders had DM. ${ }^{8}$

Increased risk of cardiovascular disorders in type $2 \mathrm{DM}$ patients is closely related with plasma NO levels. NO of endothelial origin has a key role in the maintenance of vascular homeostasis. Decrease in NO levels leads to endothelial dysfunction and atherosclerosis. ${ }^{4}$ Measurements of intracellular endothelial NO were employed in animal experiments.

Table 2 Comparison of serum ADMA, CRP, and fibrinogen levels in vildagliptin user and nonuser groups

\begin{tabular}{lcccc}
\hline & $\begin{array}{l}\text { Metformin } \\
(\mathbf{n}=35)\end{array}$ & & $\begin{array}{l}\text { Met-vildagliptin } \\
(\mathbf{n}=33)\end{array}$ & P-value \\
\cline { 2 - 3 } \cline { 5 - 5 } & Mean $\pm \mathbf{S D}$ & & Mean $\pm \mathbf{S D}$ & \\
\hline ADMA $(\mu \mathrm{mol} / \mathrm{L})$ & $0.90 \pm 0.21$ & & $0.67 \pm 0.22$ & $<0.00 \mathrm{I}$ \\
CRP $(\mathrm{mg} / \mathrm{L})$ & $3.6 \pm 5.7$ & & $4.1 \pm 4.8$ & 0.34 \\
Fibrinogen $(\mathrm{mg} / \mathrm{dL})$ & $348.5 \pm 93.2$ & & $373.2 \pm 73.7$ & 0.23 \\
\hline
\end{tabular}

Note: Fibrinogen $100-500 \mathrm{mg} / \mathrm{dL}$.

Abbreviations: SD, standard deviation; ADMA, asymmetric dimethylarginine $(0.26-0.64 \mu \mathrm{mo} / \mathrm{L})$ ); CRP, C-reactive protein $(<5 \mathrm{mg} / \mathrm{L})$; Met-vildagliptin, metformin + vildagliptin.

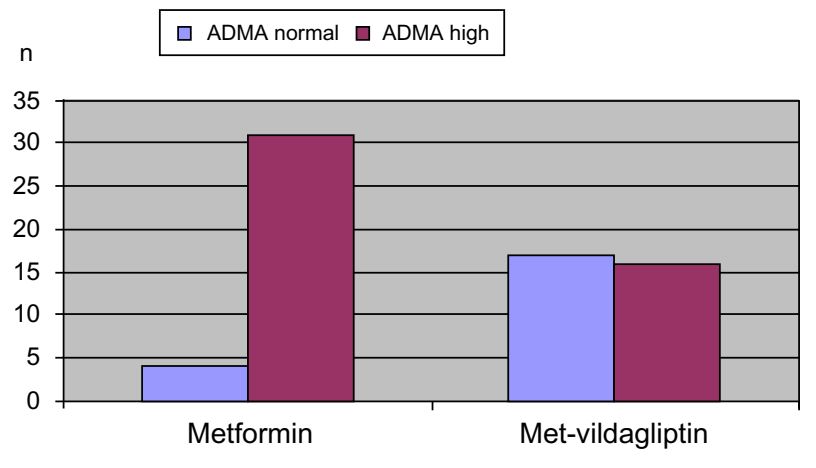

Figure I Comparison of number of patients with normal or increased ADMA levels among patient groups.

Abbreviations: ADMA, acetyl dimethylarginine; Met-vildagliptin, metformin + vildagliptin.

Measuring intracellular endothelial NO levels at the endothelial level is impossible in human studies. In humans, serum ADMA levels are measured instead, being an endogenous inhibitor of endothelial NO synthase. ${ }^{9}$ Together with the increase in serum ADMA levels, it was shown that production of NO decreases with consequent endothelial dysfunction and cardiovascular events. ${ }^{9}$ Upon the recognition of the importance of endothelial dysfunction in atherosclerosis, ADMA has been acknowledged as a significant marker of cardiovascular risk. ${ }^{10}$

Serum ADMA levels were shown to be increased in diabetics. ${ }^{4}$ These findings suggest that increase in serum ADMA in diabetics is a strong indicator of increased cardiovascular risk. ${ }^{4}$ However, there is no known efficient treatment in diabetics to lower serum ADMA concentration, the indicator of increased cardiovascular risk.

Studies on the influence of DPP-4 inhibitors, a drug class being increasingly used recently, on the cardiovascular system have attracted attention. DPP-4 inhibitors increase the concentration of GLP-1 in blood by inhibiting the DPP-4 enzyme, which breaks up endogenous GLP-1. Studies are being conducted to examine the effects of endogenous GLP-1 on the endothelium and cardiovascular system, along with a number of other body organs. The results of these studies are inconsistent. ${ }^{11-13}$

In an animal study in the literature, saxagliptin was used in obese rats, and aortic and glomerular endothelial NO levels were measured. This study also found significant endothelial NO increases in animals treated with saxagliptin $(P<0.001){ }^{7}$ In another animal study, the vildagliptin analog PFK275055 was given to obese, prediabetic rats, and the ischemic area following myocardial infarction was demonstrated to be smaller. ${ }^{12}$ In a study on humans with small patient groups, 72-hour GLP-1 infusion was administered to a subgroup of 
nondiabetic patients who had experienced acute myocardial infarction in addition to standard treatment, and regional and global left ventricular functions were shown to be improved. ${ }^{13}$ Another study determined maintenance of cardiac functions by means of GLP-1 in genetically DPP-4-deficient animals. ${ }^{14}$ In another rat study, chronic GLP-1 treatment was shown to increase survival through maintenance of cardiac functions. ${ }^{5}$ The findings obtained in these studies support the results of our study.

Looking at the literature, there are also studies reporting contradictory results to our study. An animal study included nondiabetic rats, and the impact of vildagliptin treatment on cardiac functions following acute myocardial infarction was investigated. After a treatment period of 12 weeks, comparison with the control group failed to show any significant difference. ${ }^{11}$ Sitagliptin was given to rats rendered diabetic in another study, and it was found not to exhibit sufficient cardioprotective effects. ${ }^{15}$ These being animal studies, the use of nondiabetic rats or rats rendered diabetic by means of drugs, investigation of the effects of DPP-4 inhibitors after the development of cardiac injury, and ambiguity in the adequacy of drug doses used and treatment duration, are among the features that can be criticized.

Type 2 DM, as already known, is a chronic and progressive disease. The duration of the disease is a significant factor in the development of macrovascular and microvascular complications in diabetes. Our study included patients with a mean duration of diabetes of 3.8 years, whose blood glucose levels were generally under regulation. In the studies conducted up to now, patients with already developed cardiovascular injury were examined and effects of medicines evaluated. ${ }^{11-14}$ In diabetic patients, it is hard to demonstrate the impact of medicines on cardiovascular protection once cardiovascular injury has developed. However, it is commonly acknowledged that treatments administered before the development of cardiovascular injury might be efficacious. We too preferred patients with no or lower cardiovascular risks. Therefore, the stability of levels of CRP and fibrinogen, the risk indicators expected to increase in ischemic heart disease, might have arisen from this fact. Moreover, the higher CRP concentration found in vildagliptin users, albeit insignificant, might have been caused by the longer duration of diabetes in these patients.

Compared to patients using metformin, another point is the observation of a significant decrease in serum ADMA levels in vildagliptin users, despite the unchanged blood glucose levels. This might suggest that the decrease in serum
ADMA level might be related to vildagliptin activity, independent of blood glucose regulation. Similar results were also obtained in a study conducted with saxagliptin. ${ }^{7}$

\section{Limitations}

Because this study was conducted on humans, the distribution may not have been homogeneous between the patient groups, since there are numerous factors that might affect ADMA levels. The number of patients studied was rather low, due to the widened exclusion criteria with the attempts to decrease the risks influencing ADMA levels. Although ADMA levels examined in patients are considered an indirect indicator of cardiovascular risk, the counterpart of this in decreasing risk in patients is not known. ADMA levels were not measured before starting vildagliptin treatment. Because subjects were matched with regard to age, BMI, sex, diabetes duration, and all other metabolic characteristics (Table 1), we assume that subjects in both groups had a similar baseline AMDA level.

\section{Conclusion}

Vildagliptin treatment was observed to lower serum ADMA levels, which is considered one of the cardiovascular risk indicators in patients with type 2 DM. This finding should be supported with larger-scale prospective randomized controlled studies to conclude that vildagliptin provides cardiovascular protection along with diabetes regulation.

\section{Disclosure}

The authors report no conflicts of interest in this work.

\section{References}

1. Rydén L, Standl E, Bartnik M, et al. Guidelines on diabetes, pre-diabetes, and cardiovascular diseases: executive summary. The Task Force on Diabetes and Cardiovascular Diseases of the European Society of Cardiology (ESC) and of the European Association for the Study of Diabetes (EASD). Eur Heart J. 2007;28(1):88-136.

2. Kim W, Egan JM. The role of incretins in glucose homeostasis and diabetes treatment. Pharmacol Rev. 2008;60(4):470-512.

3. Deacon CF, Wamberg S, Bie P, Hughes TE, Holst JJ. Preservation of active incretin hormones by inhibition of dipeptidyl peptidase IV suppresses meal-induced incretin secretion in dogs. J Endocrinol. 2002;172(2):355-362.

4. Cavusoglu E, Ruwende C, Chopra V, et al. Relation of baseline plasma ADMA levels to cardiovascular morbidity and mortality at two years in men with diabetes mellitus referred for coronary angiography. Atherosclerosis. 2010;210(1):226-231.

5. Poornima I, Brown SB, Bhashyam S, Parikh P, Bolukoglu H, Shannon RP. Chronic glucagon-like peptide-1 infusion sustains left ventricular systolic function and prolongs survival in the spontaneously hypertensive, heart failure-prone rat. Circ Heart Fail. 2008;1(3):153-160.

6. Antoniades C, Demosthenous M, Tousoulis D, et al. Role of asymmetrical dimethylarginine in inflammation-induced endothelial dysfunction in human atherosclerosis. Hypertension. 2011;58(1):93-98. 
7. Mason RP, Jacob RF, Kubant R, et al. Effect of enhanced glycemic control with saxagliptin on endothelial nitric oxide release and CD40 levels in obese rats. J Atheroscler Thromb. 2011;18(9):774-783.

8. Kotseva K, Wood D, De Backer G, De Bacquer D, Pyörälä K, Keil U. EUROASPIRE III: a survey on the lifestyle, risk factors and use of cardio protective drug therapies in coronary patients from 22 European countries. Eur J Cardiovasc Prev Rehabil. 2009;16(2):121-137.

9. Vallance P, Leone A, Calver A, Collier J, Moncada S. Accumulation of an endogenous inhibitor of nitric oxide synthesis in chronic renal failure. Lancet. 1992;339(8793):572-575.

10. Sibal L, Agarwal SC, Home PD, Boger RH. The role of asymmetric dimethylarginine (ADMA) in endothelial dysfunction and cardiovascular disease. Curr Cardiol Rev. 2010;6(2):82-90.

11. Yin M, Silljé HH, Meissner M, van Gilst WH, de Boer RA. Early and late effects of the DPP-4 inhibitor vildagliptin in a rat model of postmyocardial infarction heart failure. Cardiovasc Diabetol. 2011;10:85.
12. Huisamen B, Genis A, Marais E, Lochner A. Pre-treatment with a DPP-4 inhibitor is infarct sparing in hearts from obese, pre-diabetic rats. Cardiovasc Drugs Ther. 2011;25(1):13-20.

13. Nikolaidis LA, Mankad S, Sokos GG, et al. Effects of glucagon-like peptide- 1 in patients with acute myocardial infarction and left ventricular dysfunction after successful reperfusion. Circulation. 2004;109(8): 962-965.

14. Ku HC, Chen WP, Su MJ. DPP4 deficiency preserves cardiac function via GLP-1 signalling in rats subjected to myocardial ischemia/ reperfusion. Naunyn Schmiedebergs Arch Pharmacol. 2011;384(2): 197-207.

15. Sauvé M, Ban K, Momen MA, et al. Genetic deletion or pharmacological inhibition of dipeptidyl peptidase-4 improves cardiovascular outcomes after myocardial infarction in mice. Diabetes. 2010;59(4) 1063-1073.

\section{Publish your work in this journal}

Drug Design, Development and Therapy is an international, peerreviewed open-access journal that spans the spectrum of drug design and development through to clinical applications. Clinical outcomes, patient safety, and programs for the development and effective, safe, and sustained use of medicines are a feature of the journal, which has also been accepted for indexing on PubMed Central. The manuscript management system is completely online and includes a very quick and fair peer-review system, which is all easy to use. Visit http://www.dovepress.com/testimonials.php to read real quotes from published authors.

Submit your manuscript here: http://www.dovepress.com/drug-design-development-and-therapy-journal 